\title{
Simultaneous Detection of Tartrazine-Sunset Yellow in Food Samples Using Bioxide/Carbon Paste Microcomposite with Lanthanum and Titanium
}

\author{
Edgar Nagles ${ }^{1 *}$, Mario Ceroni ${ }^{1}$, and John Hurtado ${ }^{2}$ \\ ${ }^{1}$ Facultad de Química e Ingeniería Química, Universidad Nacional Mayor de San Marcos, Lima, Perú \\ ${ }^{2}$ Departamento de Química, Universidad de los Andes, Carrera 1 No. 18A-12, Bogotá, Colombia
}

\begin{abstract}
This report describes the simultaneous detection of the two dyes most commonly used in food, tartrazine (TZ) and sunset yellow (SY), based on a microcomposite of carbon paste decorated with $\mathrm{La}_{2} \mathrm{O}_{3}$ and $\mathrm{TiO}_{2}$. Anodic currents for $\mathrm{SY}-\mathrm{TZ}$ were observed at $0.89-1.21 \mathrm{~V}$ by cyclic voltammetry (CV) separated with a $\Delta \mathrm{V}$ of $0.32 \mathrm{~V}$. The increased anodic peak currents compared to that of the unmodified carbon paste electrode were almost 50 and $41 \%$ for SY-TZ, respectively. The detection limits with the optimal amount of $\mathrm{La}_{2} \mathrm{O}_{3}-\mathrm{TiO}_{2}$ were 0.02 and $0.03 \mu \mathrm{mol} / \mathrm{L}$, respectively. The relative standard deviation (RSD) based on fifty measurements was less than $3 \%$. The versatility and novelty of the sensor were tested with food samples containing these substances and other substances.
\end{abstract}

Keywords : Tartrazine, Sunset Yellow, Lanthanum And Titanium Oxides, Carbon Paste

Received : 8 June 2020, Accepted : 11 August 2020

\section{Introduction}

The use of metal oxides in the modification of carbon electrodes applied in the development of new electroanalytical methodologies has increased in recent years, mainly due to the properties of these substances, such as their high ionic conductivity, thermal stability and chemical inertness [1]. In this context, the use of metal oxides bound with other substances has been reported to detect dyes, such as $\mathrm{ZnO}$ with cysteic acid for SY-TZ [2], ZnO with poly (paminobenzensulfonic acid) for $\mathrm{TZ}$ [3], and $\mathrm{MnO}_{2}$ with reduced graphene oxide [4], $\mathrm{Dy}_{2} \mathrm{O}_{3}$ with carbon nanotubes [5], and $\mathrm{ZnO}$ with reduced graphene oxide [6] for SY. In these previous reports, detection limits were observed below $0.09 \mu \mathrm{mol} / \mathrm{L}$ and below $0.01 \mu \mathrm{mol} / \mathrm{L}$ in some cases, making substances more sensitive but also more complex to manufacture. Reports for the simultaneous detection of SY-TZ are more rare, and

*E-mail address: enaglesV@unmsm.edu.pe

DOI: https://doi.org/10.33961/jecst.2020.01067

This is an open-access article distributed under the terms of the Creative Commons Attribution Non-Commercial License (http://creativecommons.org/licenses/by-nc/4.0) Attribution Non-Commercial License (http://creativecommons.org/licenses/by-nc/4.0)
which permits unrestricted non-commercial use, distribution, and reproduction in any which permits unrestricted non-commercial use, distrib
medium, provided the original work is properly cited. the $\Delta \mathrm{V}$ value is greater than $0.1 \mathrm{~V}$. In the development of electrodes modified only with metal ion oxides to detect dye colors, the use of $\mathrm{Nd}_{2} \mathrm{O}_{3}$ for $\mathrm{SY}$ $\mathrm{TZ}$ [7], $\mathrm{ZnO}$ for $\mathrm{SY}[8]$ and $\mathrm{Co}_{3} \mathrm{O}_{4}$ for allura red [9] without being combined with other substances, such as nanomaterials, has been reported. The detection limits reported were below $0.09 \mu \mathrm{mol} / \mathrm{L}$. Therefore, these reports indicate sensitivity equal to that when metal oxides are used in combination with other substances, such as those mentioned above. Lanthanum (III) oxide has not been used to detect SY-TZ but has been used to detect thimerosal combined only with carbon paste [10]. Combinations with other substances, such as carbon nanotubes and graphene, have been used to detect biological substances $[11,12]$ and pharmacological substances [13-15]. These reports are evidence of the great versatility of $\mathrm{La}_{2} \mathrm{O}_{3}$ in the modification of electrodes applied to detect different analytes, in this case, dyes. The use of $\mathrm{TiO}_{2}$ to detect TZ-SY without other substances has not been reported, but $\mathrm{TiO}_{2}$ combined with graphene was reported to detect SY-TZ with a detection limit below $0.009 \mu \mathrm{mol} / \mathrm{L}$ with carbon paste [16] and glassy carbon [17]. The authors indicated that the great sensitivity was due to the high accumulation 
effect and great catalytic capability of graphene and mesoporous $\mathrm{TiO}_{2}$. This new method may achieve the same effect simply by omitting the accumulation effect that should have been the product of the presence of graphene but providing a simpler electrode. Moreover, the combined use of La and Ti from the synthesis of different ligands has been employed for the electrochemical detection of nitrite [1]. The authors indicated that the high sensitivity below $0.09 \mu \mathrm{mol} / \mathrm{L}$ was due to the larger pore size found at the higher sintering temperature and $\mathrm{pH}$, which presents a good development at high temperatures of $70^{\circ} \mathrm{C}[18]$. One of the few reports where combined metal oxides were used to detect SY-TZ used Fe and Si [19], but combined with carbon nanotubes, where the authors achieved a detection limit of less than $0.09 \mu \mathrm{mol} / \mathrm{L}$, very close to the detection limit reported in this study. The reason for studying these dyes in foods is the same reason that motivated the studies reported above. These substances are used commonly in almost all foods to improve their appearance and stability. However, they can negatively affect people's health, especially children's health, when they are consumed frequently and are a potential cause of attentiondeficit/hyperactivity disorder (ADHD). [20]. Many reports have been developed in recent years to detect SY and TZ using different techniques such as spectrocopy and chromatographic techniques coupled to UV / Vis detectors [21,22]. These studies have reported great sensitivity, but they have the disadvantage of the high cost of instruments and sample treatment.

On the other hand, electroanalytical techniques have been a great equally sensitive alternative but with the advantage of having a low cost. Furthermore, it is a very versatile technique used to detect different types of analytes using modified electrodes such as biological substances, for example dopamine, ascorbic acid, uric acid, folic acid, guanine and glucose [23-27]. Also, medicaments and compounds such as ranitidine and metronidazole [28], nitric oxide [29] and hydrogen peroxide [30].

The aim and novelty of this work are justified based on the few reports describing methodologies to detect SY-TZ using simple and inexpensive electrodes.

\section{Experimental}

\subsection{Reagents and instruments}

$\mathrm{La}_{2} \mathrm{O}_{3}-\mathrm{TiO}_{2}$, the dyes TZ-SY and others such as allura red (AR), amaranth (AM) and ponceau 4-R (PR), were obtained from Sigma-Aldrich. Only twenty milliliters of standard solutions at $1.0 \mathrm{mmol} / \mathrm{L}$ and $0.1 \mathrm{mmol} / \mathrm{L} \mathrm{TZ-SY}$ were used throughout the study. Type A water (ultrapure) was obtained from a Wasselab ASTM D1193 purifier system. Phosphate buffer solution (PBS), borate buffer solution (BBS) and acetate buffer solution (ABS) were used as the electrolytes at $\mathrm{pH}$ values of 2.0-7.0, 10.0 and 4.0, respectively. An Autolab PGSTAT204 potentiostat/ galvanostat from Metrohm (Switzerland) was used to perform CV and square wave voltammetry (SWV). An Orion-430 digital $\mathrm{pH} / \mathrm{mV}$ meter equipped with a combined $\mathrm{pH}$ glass electrode was used for $\mathrm{pH}$ measurements.

\subsection{Microcomposite preparation with $\mathrm{LaO}_{3}-\mathrm{TiO}_{2}$}

Three working electrodes based on a carbon paste powder were prepared following an order previously reported only for $\mathrm{La}_{2} \mathrm{O}_{3}[10]$. First, an unmodified carbon paste electrode (PCE) using $50.0 \mathrm{mg}$ of graphite powder and $20 \mu \mathrm{L}$ of paraffin oil. Second, a modified carbon paste electrode using $50.0 \mathrm{mg}$ of graphite powder with $5.0 \mathrm{mg}$ of $\mathrm{TiO}_{2}\left(\mathrm{Ti}_{\mathrm{OX}} / \mathrm{CPE}\right)$ and $20 \mu \mathrm{L}$ of paraffin oil. Third, a modified carbon paste electrode using $50.0 \mathrm{mg}$ of graphite powder with $10.0 \mathrm{mg}(1: 1)$ of $\mathrm{La}_{2} \mathrm{O}_{3}-\mathrm{TiO}_{2}\left(\mathrm{La}-\mathrm{Ti}_{\mathrm{OX}} / \mathrm{CPE}\right)$ and $20 \mu \mathrm{L}$ of paraffin oil. All the electrodes were compacted and supported inside a PVC cylinder with a copper wire for the electrical contact. The fresh surfaces were cleaned to obtain a smooth-looking surface. The same electrode was used several times only by removing excess adsorbed material after a series of measurements. The optimal amount of metals oxides was $5.0 \mathrm{mg}$, with $50.0 \mathrm{mg}$ of carbon powder for all the electrodes that were prepared in this work.

\subsection{Sample preparation}

The samples were obtained from a supermarket in the city of Lima, Perú. Many of these samples contained the simultaneous presence of SY-TZ, while others contained only SY and were of a complex matrix since they contained other substances, such as protein, ascorbic acid, carboxymethylcellulose, citric acid, fumaric acid, sodium citrate aspartame and sugar. Solid samples, such as orange juice powder, were weighed and diluted 10 times with ultrapure water. Liquid samples, such as orange juice and mandarin isotonic drink, were not diluted before the anal- 
ysis, and an aliquot of $50.0 \mu \mathrm{L}$ was enough to observe the anodic peak currents. No pretreatment to eliminate possible interference was necessary before each analysis.

\subsection{Measurement procedure}

The electrochemical measurements were developed by $\mathrm{CV}$ and square wave voltammetry (SWV) with a cell that contained $9.5 \mathrm{~mL}$ of ultrapure water, $0.50 \mathrm{ml}$ of $0.10 \mathrm{~mol} / \mathrm{L}$ electrolyte solution (PBS, BBS and $\mathrm{ABS}$ ) and $100 \mu \mathrm{L}$ of $1.0 \mathrm{mmol} / \mathrm{L} \mathrm{TZ-SY}$ at 0.1 $\mathrm{V} / \mathrm{s}$ by $\mathrm{CV}$ and between 10.0 and $100.0 \mu \mathrm{L}$ of 0.1 $\mathrm{mmol} / \mathrm{L}$ TZ-SY by an SWV technique with a frequency of $10 \mathrm{~Hz}$ and a pulse amplitude of $0.05 \mathrm{~V}$ at $0.0 \mathrm{~V}$ for $10 \mathrm{~s}$.

\section{Results and Discussion}

3.1 Electrochemical characterization using $\mathrm{K}_{4} \mathrm{Fe}(\mathrm{CN})_{6}$ by $\mathrm{CV}$ and SY-TZ activity by SWAdV on the carbon paste electrode decorated with $\mathrm{TiO}_{2}$ and $\mathrm{La}_{2} \mathrm{O}_{3}-\mathrm{TiO}_{2}$

The electroactive properties of the bioxide composite ( $\mathrm{La}-\mathrm{Ti}_{\mathrm{OX}} / \mathrm{CPE}$ ) were evaluated by $\mathrm{CV}$ using $\mathrm{K}_{4} \mathrm{Fe}(\mathrm{CN})_{6}$ in $10.0 \mathrm{mmol} / \mathrm{L} \mathrm{KCl}$ as a model electrolyte (Fig. 1A) and $10.0 \mu \mathrm{mol} / \mathrm{L} \mathrm{SY-TZ} \mathrm{(Fig.} \mathrm{1B-C)} \mathrm{on} \mathrm{CPE} \mathrm{(curve} \mathrm{a),}$ $\mathrm{Ti}_{\mathrm{OX}} / \mathrm{CPE}$ (curve $\mathrm{b}$ ) and $\mathrm{La}-\mathrm{Ti}_{\mathrm{OX}} / \mathrm{CPE}$ (curve $\mathrm{c}$ ) by $\mathrm{CV}$ and SWAdV. Before beginning to describe the results of this section (Fig. 1), the authors confirmed that redox processes attributed to the metal oxides deposited on the carbon paste surface were not observed at potential values between 0.0 and $1.5 \mathrm{~V}$.

On the other hand, carbon paste electrode modified only with $\mathrm{La}_{2} \mathrm{O}_{3}\left(\mathrm{La}_{\mathrm{OX}} / \mathrm{CPE}\right)$ did not show significant activity with the dyes. Therefore, no curves are shown in this report using this electrode. The results clearly showed that the potential values were not affected by the presence of the oxides. Therefore, we cannot confirm an electrocatalytic process. On the other hand, the anodic and cathodic peak current values for the $\mathrm{Fe}^{3+} / \mathrm{Fe}^{2+}$ redox system were higher and the $\Delta \mathrm{I}_{\mathrm{p}}(\mu \mathrm{A})$ was lower with La-Ti $\mathrm{O}_{\mathrm{OX}} / \mathrm{CPE}$ (Fig. 1A curve $\mathrm{c})$, making the systems less quasi-reversible. Previous studies confirmed the effect that $\mathrm{La}_{2} \mathrm{O}_{3}$ has on the $\mathrm{Fe}^{3+} / \mathrm{Fe}^{2+}$ redox system, with an anodic peak current at $0.4 \mathrm{~V}$ and an intensity current close to $350.0 \mu \mathrm{A}[10]$. In this case, the presence of $\mathrm{La}_{2} \mathrm{O}_{3}$ $\mathrm{TiO}_{2}$ allows the redox process to occur at potential values less than $0.4 \mathrm{~V}$, but with a considerable decrease in the anodic current, which was $191 \mu \mathrm{A}$.
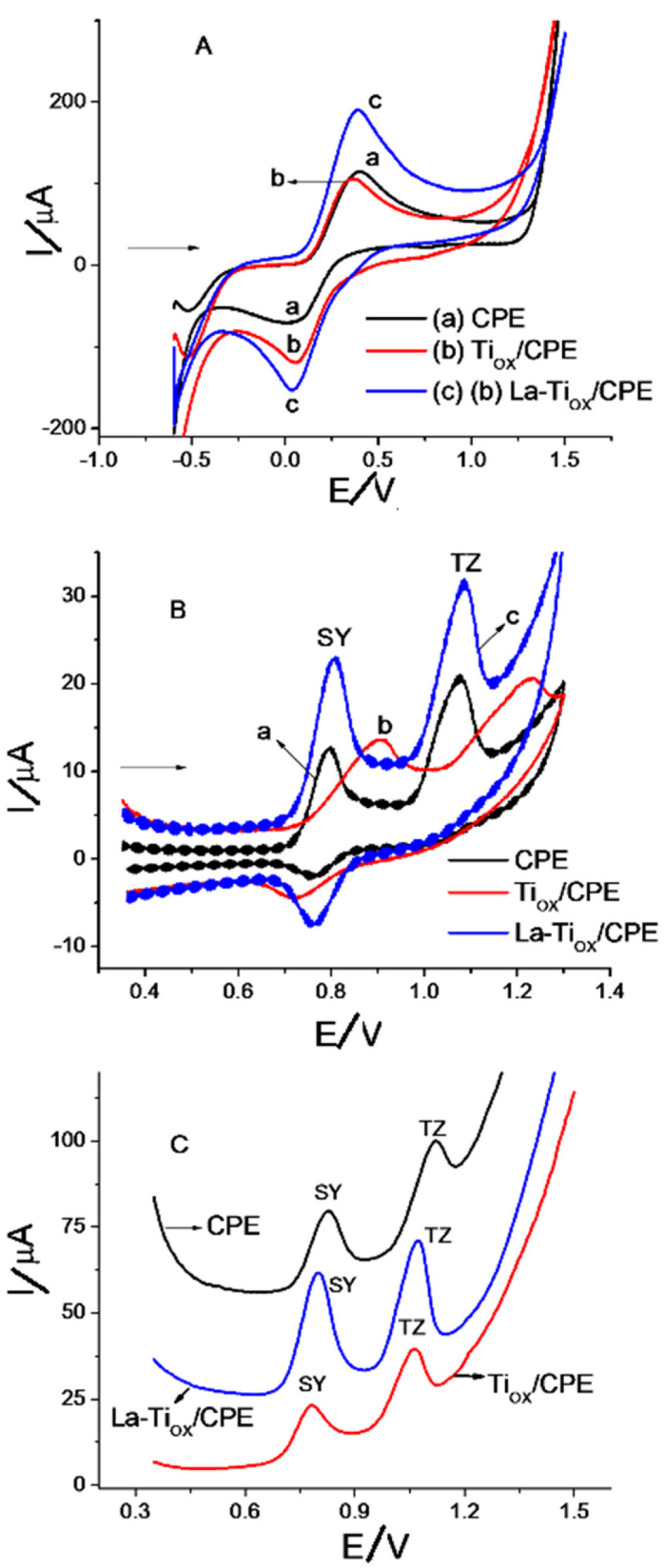

Fig. 1. Cyclic voltammograms for CPE (curve a), Ti $\mathrm{OX}_{\mathrm{OX}} /$ CPE (curve b) and La-Ti OX $/ \mathrm{CPE}$ (curve c) with (A) 10.0 $\mathrm{mmol} / \mathrm{L} \mathrm{Fe}(\mathrm{CN})_{6}^{-3 / 4}$ in $10.0 \mathrm{mmol} / \mathrm{L} \mathrm{KCl}$ and $10.0 \mathrm{~mol} / \mathrm{L}$ SY-TZ by CV (B) and SWV (C). Conditions: $\mathrm{pH}, 2.0$; scan rate, $0.1 \mathrm{v} / \mathrm{s}$; frequency, $10.0 \mathrm{~Hz}$; pulse amplitude, $0.05 \mathrm{~V}$; potential accumulation, $0.0 \mathrm{~V}$ by $10.0 \mathrm{~s}$.

Moreover, with other oxides, such as Co, signal values greater than $0.5 \mathrm{~V}$ were reported [9]. It should be 
Table 1. Anodic peak current increases and potential values for TZ-SY with $\mathrm{CPE}, \mathrm{Ti}_{\mathrm{OX}} / \mathrm{CPE}$ and $\mathrm{La}-\mathrm{Ti}_{\mathrm{OX}} / \mathrm{CPE}$ by SWAdV

\begin{tabular}{|c|c|c|c|c|c|c|}
\hline \multirow[t]{2}{*}{ Electrode } & \multicolumn{2}{|c|}{$\operatorname{SWV}(\mu \mathrm{A})$} & \multicolumn{2}{|c|}{$\%$ Anodic Current Increase } & \multicolumn{2}{|c|}{ Potential (V) } \\
\hline & SY & $\mathrm{TZ}$ & SY & $\mathrm{TZ}$ & SY & $\mathrm{TZ}$ \\
\hline $\mathrm{CPE}$ & 16.3 & 8.9 & & & 0.82 & 1.11 \\
\hline $\mathrm{Ti}_{\mathrm{OX}} / \mathrm{CPE}$ & 7.14 & 12.0 & -0.0 & 5.00 & 0.77 & 1.05 \\
\hline $\mathrm{La}-\mathrm{Ti}_{\mathrm{OX}} / \mathrm{CPE}$ & 32.30 & 32.2 & 50.0 & 45.0 & 0.77 & 1.05 \\
\hline
\end{tabular}

concluded that the presence of $\mathrm{TiO}_{2}$ decreases the effect that $\mathrm{La}_{2} \mathrm{O}_{3}$ has on the $\mathrm{Fe}^{3+} / \mathrm{Fe}^{2+}$ system, as previously reported [10], but increases the activity on

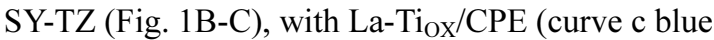
color) on the anodic peak currents of SY-TZ is clearly observed. These values were increased almost 50\% by $\mathrm{CV}$ and SWV. On the other hand, the potential values did not show changes in response to CV but in response to SWV, and the oxidation of SY-TZ happened at less positive potential values. These results indicate that the presence of $\mathrm{La}_{2} \mathrm{O}_{3}-\mathrm{TiO}_{2}$ on the surface of the electrode increases the rate of charge transfer and decreases the energy needed to oxidize SY-TZ, possibly due to the previously reported properties of these oxides such as increasing the superficial area and the formation of electrostatic interactions $[1,7]$. The current and potential values observed with the three electrodes by SWV are summarized in Table 1. It is clearly observed that the highest anodic peak current for SY-TZ was with the $\mathrm{La}-\mathrm{Ti}_{\mathrm{OX}} / \mathrm{CPE}$ microcomposite, while the lowest current was with $\mathrm{Ti}_{\mathrm{OX}} / \mathrm{CPE}$. Therefore, the composite was used in subsequent analyses because it presented greater activity in the electrochemical oxidation of SY-TZ. The potential values observed in this work were very similar to those in previous reports where $\mathrm{Zn}$ [6] and $\mathrm{Ti}$ [16] oxides were used. Conversely, a lower value of considerable potential with a $\Delta \mathrm{V}$ higher for SY-TZ was with $\mathrm{Dy}_{2} \mathrm{O}_{3}$ [5].

3.2 Study of significant variables that improve the sensitivity and stability of the new method with La-Ti OX $_{\text {CPE: }} \mathbf{p H}$ and mass transfer

The $\mathrm{pH}$ effect was studied in order to identify the optimum $\mathrm{pH}$ of the highest anodic current and obtain a higher slope value in the development of a calibration curve, and the mass transferences were studied as a function of the scan rate with the objective of identifying a diffusive process that has a smaller memory effect on electrode surface and greater reproducibility between measurements or, in contrast, an adsorptive process. These processes have been extensively studied with other modified electrodes where the anodic current generally changes to less positive potential values with an increase in $\mathrm{pH}$, with slope values of almost half the theoretical value of $0.059 \mathrm{pH}$, which indicates that protons are involved in the process in a $1 \mathrm{H}^{+}: 1 \mathrm{e}^{-}$ratio $[16,31,32]$. In contrast, diffusion-controlled processes have been reported with carbon paste, glassy carbon and screenprinted electrode carbon electrodes $[3,16,31,33]$ and controlled by adsorption processes with vitreous carbon-based electrodes [5].

In this report, $\mathrm{pH}$ was varied between 2.0 and 10.0. The maximum anodic peak currents were observed at $\mathrm{pH}$ values of 2.0 and 7.0 with PBS. With other electrolyte supports, such as BBS and ABS, the anodic peak currents were lower (Fig. 2A). On the other hand, the shift in the potential was the same as that mentioned in previous reports [16,31,32]. The anodic peak shifted to a less positive potential value with a $\mathrm{pH}$ increase for SY-TZ with a regression equation of $\mathrm{I}_{\mathrm{p}}(\mu \mathrm{A})=0.877+0.033 p H$ for $\mathrm{SY}$ and $\mathrm{I}_{\mathrm{p}}(\mu \mathrm{A})=$ $1.167+0.038 p H$ for TZ (Fig. 2B). The slope values of 0.033 and $0.038 \mathrm{~V} / \mathrm{pH}$ obtained for SY-TZ are almost half the value of the theoretical Nernst constant of $0.059 \mathrm{~V} / \mathrm{pH}$, implying that in this process, one electron is transferred. A pH of 2.0 (PBS) was chosen for further analysis. SY-TZ mass transfer depends on whether the material can be diffused or adsorbed $[3,5]$. In this report, the mass transfer of SY-TZ was studied on $\mathrm{La}-\mathrm{Ti}_{\mathrm{OX}} / \mathrm{CPE}$ between scan rates $(v)$ of 0.01 and $0.11 \mathrm{~V} / \mathrm{s}$ to verify stability because in adsorptive processes, memory signals can be originated on the electrode due to substances that enter the internal structure of the sensor and that do not easily desorb, which affects its stability and do not allow it to be used in more than one measurement; thus, the anodic peak current values were plotted as a function of the square root of the scan rate (Fig. 2C), with a 

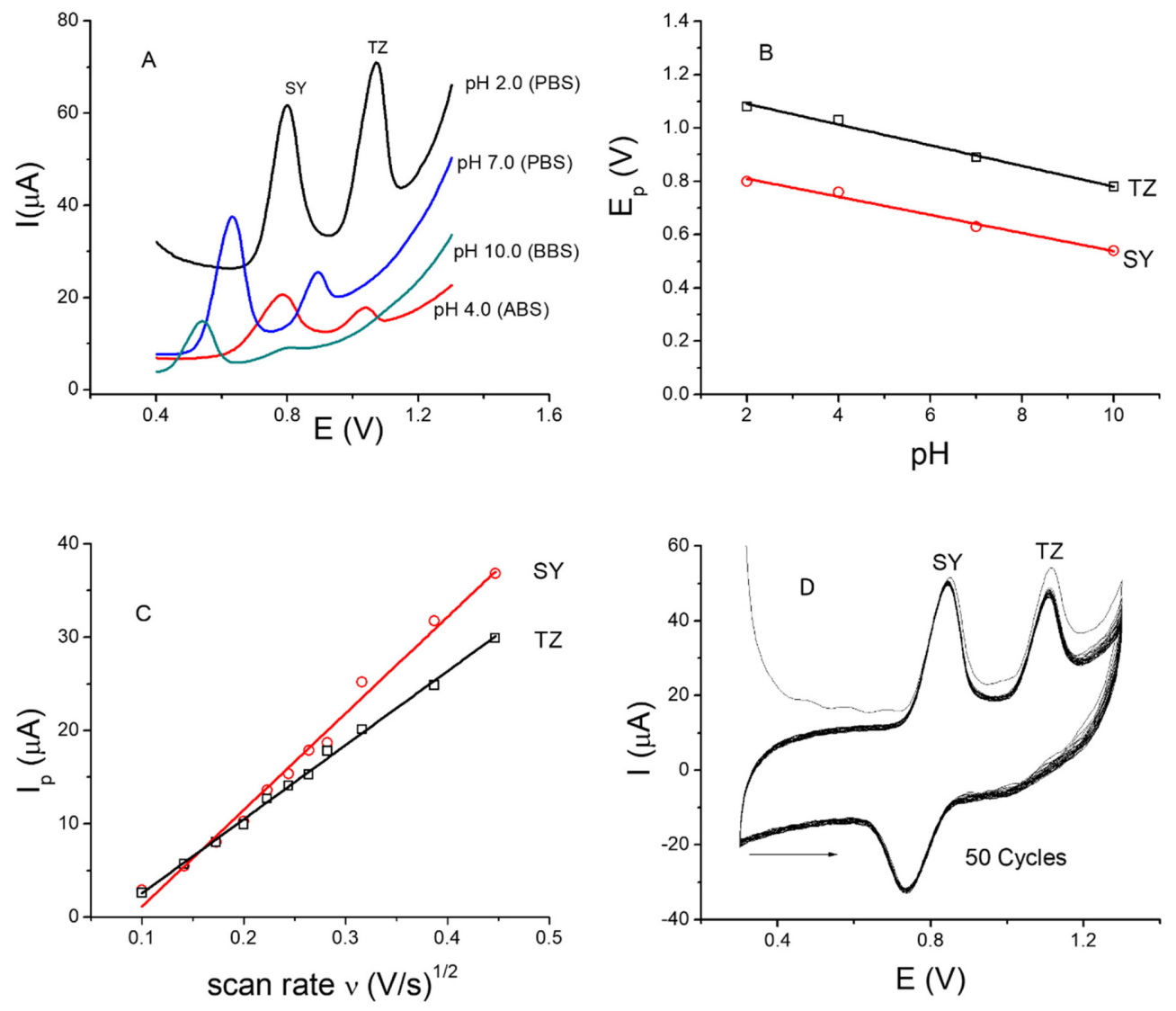

Fig. 2. (A) Cyclic voltammograms of SY-TZ $(10.0 \mu \mathrm{mol} / \mathrm{L})$ at $\mathrm{pH}$ values of $2.0,4.0,7.0$ and 10.0 , (B) effect of $\mathrm{pH}$ on the anodic peak potential and (C) effects of the square root of the scan rate on the anodic peak current and (D) Cyclic voltammetry curves (50 cycles) for La-TioX $/ \mathrm{CPS}$ containing $10.0 \mu \mathrm{mol} / \mathrm{L} \mathrm{SY-TZ} \mathrm{at} \mathrm{pH} 2.0$ (PBS) and a scan rate of $0.1 \mathrm{~V} / \mathrm{s}$. when using $\mathrm{La}-\mathrm{Ti}_{\mathrm{OX}} / \mathrm{CPE}$.

regression equation of $\mathrm{I}_{\mathrm{p}}(\mu \mathrm{A})=-9.13+130.37 v^{1 / 2}$ for $\mathrm{SY}$ and $\mathrm{I}_{\mathrm{p}}(\mu \mathrm{A})=-5.36+79.27 v^{1 / 2}$ for $\mathrm{TZ}$. The two line equations presented correlation coefficients $\left(\mathrm{R}^{2}\right)$ of 0.989 and 0.998 for SY-TZ, respectively, which are close to 1.0 , indicating a linear trend. On the other hand, for the plot of $\log \mathrm{I}_{\mathrm{p}}(\mu \mathrm{A})$ vs $\log v$ (not shown) for SY-TZ, the slope values were close to the theoretical value of 0.5 . These results indicate that the process is predominantly controlled by diffusion. However, the diffusion process allows only a small amount of variation (less than $1.5 \%$ of the anodic current value) for 50 consecutive cycles by $\mathrm{CV}$ using $10.0 \mu \mathrm{mol} / \mathrm{L} \mathrm{SY-TZ} \mathrm{(Fig.} \mathrm{2D).} \mathrm{This} \mathrm{indicates} \mathrm{a}$ decrease in the anodic peak current of $0.03 \%$ for each cycle. Therefore, the sensor can be used for a long time without considerable loss of activity.

\subsection{Detection limit and accuracy}

All optimized parameters related to sensitivity, such as $\mathrm{pH}$, amounts of $\mathrm{La}_{2} \mathrm{O}_{3}$ and $\mathrm{TiO}_{2}$, frequency (HZ), amplitude potential (AE), accumulation time $\left(\mathrm{t}_{\mathrm{ACC}}\right)$ and accumulation potential $\left(\mathrm{E}_{\mathrm{ACC}}\right)$, were similar for the SY-TZ pair; only $\mathrm{E}_{\mathrm{ACC}}$ was different. At a value of $0.0 \mathrm{~V}$, the anodic peak current for $\mathrm{SY}$ was higher than that for $\mathrm{TZ}$, and at a value of $-0.1 \mathrm{~V}$, the anodic peak current for $\mathrm{TZ}$ was higher than that for SY. Therefore, the calibration curves were developed with the following parameters: $\mathrm{pH}$ of $2.0, \mathrm{t}_{\mathrm{ACC}}$ of $10.0 \mathrm{~s}$, frequency of $10 \mathrm{~Hz}$ and potential amplitude of $0.05 \mathrm{~V}$ for SY-TZ but an $\mathrm{E}_{\mathrm{ACC}}$ of $0.0 \mathrm{~V}$ for $\mathrm{SY}$ and $0.1 \mathrm{~V}$ for TZ. Voltammogram and calibration curves (inset) obtained by SWV with SY-TZ between 0.26 and $4.5 \mu \mathrm{mol} / \mathrm{L}$ are shown in Fig. 3. Under these con- 

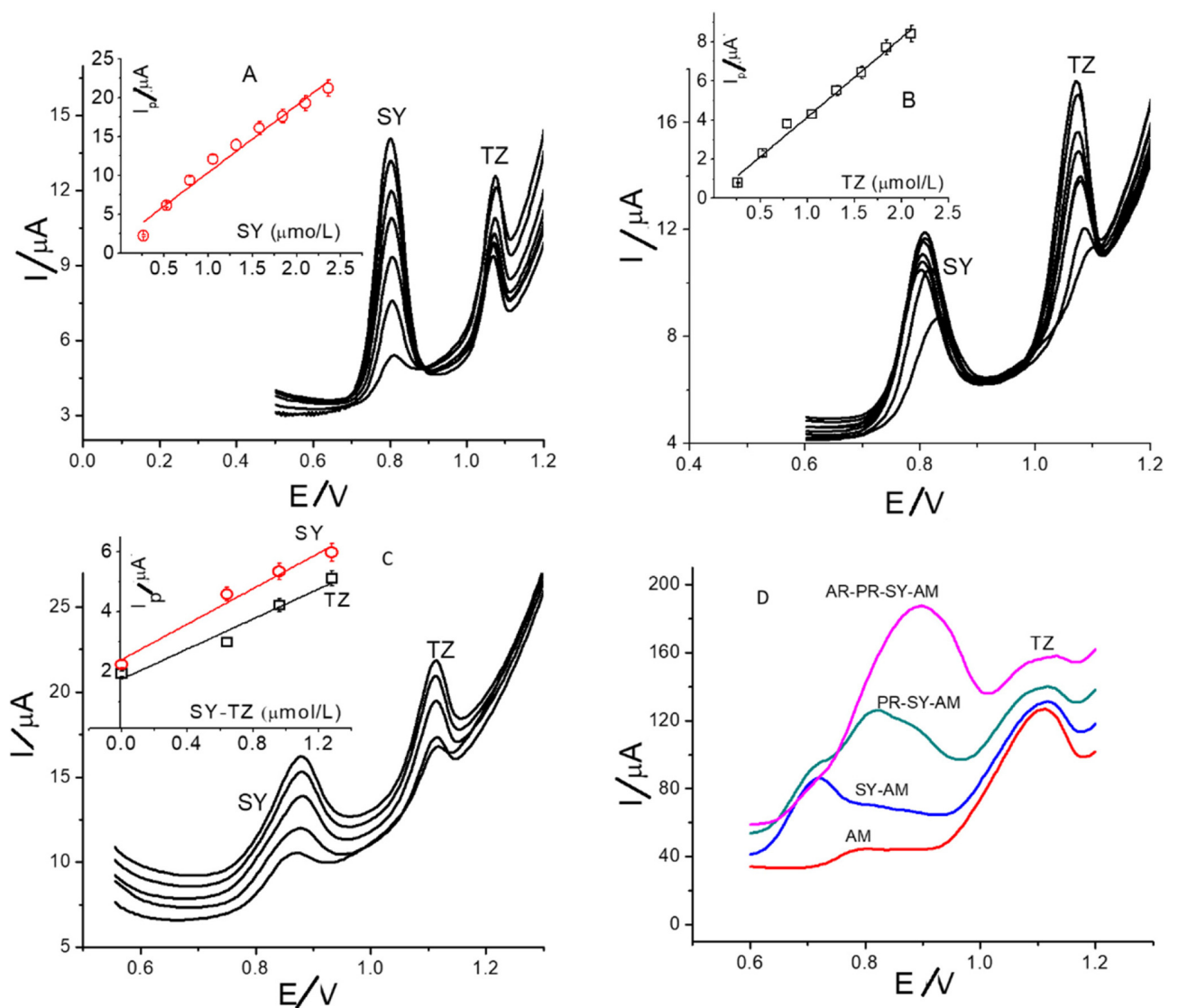

Fig. 3. Square wave voltammograms and calibration curves (inset) for (A) $S Y$ in the presence of $T Z$ and (B) $T Z$ in the presence of SY. (C) Square wave voltammograms and calibration curves (inset) for increasing concentrations of TZ-SY in unflavored gelatin and (D) square wave voltammograms of SY-TZ in the presence of AM, PR and AR at fifty-times-higher concentrations with La-Ti $\mathrm{OXX}_{\mathrm{CPE}} / \mathrm{Conditions:} \mathrm{pH}$ of 2.0 (PBS); $\mathrm{E}_{\mathrm{ACC}}$ of $0.0 \mathrm{~V}$; and $\mathrm{t}_{\mathrm{ACC}}$ of $10 \mathrm{~s}$. Other conditions as in Fig. 1.

ditions, a linear relationship between concentration $(\mu \mathrm{mol} / \mathrm{L})$ and current $(\mu \mathrm{A})$ was obtained, with a regression equation of $\mathrm{I}_{\mathrm{p}}(\mu \mathrm{A})=1.76+8.70 C_{S Y}$ with an $\mathrm{R}^{2}$ of 0.98 for $\mathrm{SY}$ in the presence of $2.0 \mu \mathrm{mol} / \mathrm{L}$ $\mathrm{TZ}$ (inset Fig. 3A) and $\mathrm{I}_{\mathrm{p}}(\mu \mathrm{A})=0.10+4.10 C_{T Z}$ with an $\mathrm{R}^{2}$ of 0.99 for $\mathrm{TZ}$ in the presence of $2.0 \mu \mathrm{mol} / \mathrm{L}$ SY (inset Fig. 3B). The detection limits obtained $(3 \sigma / \mathrm{m})$ were 0.02 and 0.03 for SY-TZ. The results show that the slope value reported for SY was higher than the value reported for $\mathrm{TZ}$, but the detection limit was lower for SY due to its smaller intercept and $\mathrm{R}^{2}$ value. It is possible that $\mathrm{TZ}$ has more activity on the microcomposite surface at low concentrations or competition effect on adsorption.

On the other hand, the lowest concentration for dyes was $0.26 \mu \mathrm{mol} / \mathrm{L}$ in the calibration curve and with this value a well defined signal was observed in Fig. 3A-B and it differs greatly from the background current. Therefore, if the concentration is lowered further, the signal will be observed. Normally with these conditions the detection limit can give up to 10 units lower compared to the lower concentration standard [24].

The versatility of the new method was compared with that in previous reports (as shown in Table 2) using electrodes modified with other metal ion oxides and substances with a higher sensitivity but that are more complex to manufacture and more expensive. In this context, this new method is equally sensitive and convenient due to its easy development. Food 
Table 2. Electroanalytical methods for SY-TZ

\begin{tabular}{|c|c|c|c|c|c|}
\hline Analyte & Modified electrode & Method & Detection limit $(\mu \mathrm{mol} / \mathrm{L})$ & Application & Ref. \\
\hline SY & $\mathrm{MoO} / \mathrm{SPCE}$ & Oxidation by DPV & 0.002 & Soft drink & {$[34]$} \\
\hline $\mathrm{TZ}$ & & & 0.002 & & \\
\hline $\mathrm{TZ}$ & ZnO-Cys/GCE & Oxidation by DPV & 0.03 & Soft drink & {$[2]$} \\
\hline SY & & & 0.01 & & \\
\hline $\mathrm{TZ}$ & $\mathrm{TiO}_{2}-\mathrm{G} / \mathrm{CPE}$ & Oxidation by SWV & 0.008 & Extracts & {$[16]$} \\
\hline SY & & & 0.006 & & \\
\hline $\mathrm{TZ}$ & $\mathrm{Cu}-\mathrm{BTC} / \mathrm{CPE}$ & Oxidation by DPV & $0.14 \mathrm{nM}$ & Soft drink & {$[35]$} \\
\hline SY & & & $0.05 \mathrm{nM}$ & & \\
\hline $\mathrm{TZ}$ & $\mathrm{La}-\mathrm{Ti}_{\mathrm{OX}} / \mathrm{CPE}$ & Oxidation by SWV & 0.03 & Soft drink & This work \\
\hline SY & & & 0.02 & & \\
\hline
\end{tabular}

SPCE: Screen-printed carbon electrode; CPE: carbon paste electrode; GCE: glassy carbon electrode; $\mathrm{ZnO} / \mathrm{Cys}$ : Zn oxide/cysteic acid; G: graphene; BTC: benzenetricarboxylate

samples contain increased amounts of SY-TZ compared to the limit of detection obtained with this new method.

\subsection{Validation and possible interferences of the new method}

The method was validated on the basis of the relative error (RE) with samples developed with nonflavored gelatin spiked with known amounts of SY-TZ. This matrix was chosen because it is complex and very similar to a real sample that contains a protein percentage of almost $12 \%$, which is useful for assessing the stability of the sensor against interfering substances. The determination was carried out using the standard addition method $(n=3)$. The obtained values for nonflavored gelatin sample 1 (additions of TZ-SY $0.40 \mu \mathrm{mol} / \mathrm{L}$ or real date (RD)) were $0.35 \pm 0.05$ and $0.45 \pm 0.04$ (experimental date (ED)) for SY-TZ, respectively, with $\mathrm{RE}$ (obtained as $\mathrm{ED}-\mathrm{RD} / \mathrm{RD} * 100$ ) values of -12.5 for $\mathrm{TZ}$ and $-12-5 \%$ for $\mathrm{SY}$ with a regression equation of $\mathrm{I}_{\mathrm{p}}(\mu \mathrm{A})=1.54+5.80 C_{S Y}$ and $\mathrm{I}_{\mathrm{p}}(\mu \mathrm{A})=1.43+5.65 C_{T Z}$. respectively. The values obtained for nonflavored gelatin sample 2 (additions of TZ-SY $0.60 \mu \mathrm{mol} / \mathrm{L} \mathrm{ED)} \mathrm{were} 0.65 \pm 0.02$ and $0.67 \pm 0.04 \mu \mathrm{mol} / \mathrm{L}$ for $\mathrm{SY}-\mathrm{TZ}$, respectively, with RE values of 8.30 and $11.6 \%$ for SY-TZ, respectively with a regression equation of $\mathrm{I}_{\mathrm{p}}(\mu \mathrm{A})=2.16+6.65 C_{S Y}$ and $\mathrm{I}_{\mathrm{p}}(\mu \mathrm{A})=2.30+6.90 \mathrm{C}_{t z}$. Fig $3 \mathrm{C}$ shows voltammograms for sample 2 . The nonflavored gelatin matrix did not affect the stability of the sensor, although anodic peak currents for SY-TZ were observed at more positive potentials. In the sample with the lowest concentration, the error was negative, indicating that only random errors occurred.

The new microcomposite showed activity towards several substances at values of potential between 0.0 and $1.5 \mathrm{~V}$, such as uric acid, dopamine, flavonoids and paracetamol. Fortunately, these substances do not coexist within the foods analyzed in this study. On the other hand, ascorbic acid, which was present in the analyzed sample, did not show activity with the microcomposite. The potential interfering substances observed in this new method include other dyes, such as allura red (AR), amaranth (AM) and ponceau 4-R (PR). These dyes interfere with the SY signal because they oxidize at near potential values of $0.8 \mathrm{~V}$. Therefore, the analyzed samples should not contain these dyes. This effect is shown in Fig. 3D.

\subsection{Analysis of real samples}

The usefulness of the new method was evaluated with synthetic orange juice, orange juice powder and tropical fruit isotonic drink. The solid samples were weighed and dissolved in $50 \mathrm{~mL}$ of ultrapure water. Liquid samples were analyzed undiluted. The results are summarized in Table 3, with their respective standard deviations and slope values. The slope values decreased considerably for SY-TZ compared with the calibration curves, indicating that this more complex matrix affects mass transfer. These detected values 
Table 3. Real-sample analysis

\begin{tabular}{|c|c|c|c|c|c|c|}
\hline Sample & Substance & $\begin{array}{c}\text { Added } \\
(\mu \mathrm{mol} / \mathrm{L})\end{array}$ & $\begin{array}{l}\text { Detected } \\
(\mu \mathrm{mol} / \mathrm{L})\end{array}$ & $\begin{array}{c}\text { Found } \\
(\mu \mathrm{mol} / \mathrm{L})\end{array}$ & $\begin{array}{c}\text { Slope } \\
\text { (m) }\end{array}$ & RDS \\
\hline \multirow{2}{*}{ synthetic orange juice } & SY & 2.50 & 4.10 & 1.60 & 2.60 & \pm 0.05 \\
\hline & $\mathrm{TZ}$ & 2.50 & 4.06 & 1.56 & 1.98 & \pm 0.04 \\
\hline \multirow{2}{*}{ orange juice powder } & SY & 2.50 & 4.55 & 2.05 & 1.22 & \pm 0.03 \\
\hline & $\mathrm{TZ}$ & 2.50 & 4.64 & 2.12 & 1.51 & \pm 0.02 \\
\hline \multirow{2}{*}{ tropical fruit isotonic drink } & SY & 2.50 & 3.08 & 0.58 & 3.00 & \multirow{2}{*}{ \pm 0.02} \\
\hline & $\mathrm{TZ}$ & - & - & - & - & \\
\hline
\end{tabular}

were very similar to those in previous reports for SYTZ using modified electrodes [3,16,33].

\section{Conclusions}

This report presents a new application of combined metal oxides. This method was simple to perform, sensitive, environmentally friendly and versatile, with different types of real samples for simultaneous SY-TZ analysis. This new method is more convenient compared to other non-electroanalytical techniques because they reduce the cost of analysis of each sample and time of the measurement. The detection limit was below $0.09 \mu \mathrm{mol} / \mathrm{L}$. Another great advantage of this new method is elimination of the treatment of the sample prior to its analysis with filtration or extraction processes. A considerable disadvantage of the method is the possible interference of other dyes, such as AR, PR and AM. However, this method can be used for many foods containing SY-TZ in the absence of other red dyes. On the other hand, it was possible to improve the activity of $\mathrm{TiO}_{2}$ that has only been improved with graphene and other more complex nano structures.

\section{Acknowledgment}

E.N. and M.C appreciates the financial support provided by the Universidad Nacional Mayor de San Marcos (project C1907068118-541 and C20071301). Additionally, J.H. thanks the Universidad de los Andes, Science Faculty and the Chemistry Department.

\section{References}

[1] M.A. Mansoor, V. McKee, F.B. Yusof, S.P. Lim, M.N.M. Zubir, H.N. Ming, and M. Mazhar, Polyhedron, 2018, 156, 332-341.
[2] P. S. Dorraji and F. Jalali, Food Chem., 2017, 227, 7377.

[3] G. Karim-Nezhad, Z. Khorablou, M. Zamani, P. S. Dorraji, and M. Alamgholiloo, J. Food Drug Anal., 2017, 25(2), 293-301.

[4] Z. Ding, P. Deng, Y.Wu, Y. Tian, G. Li, J. Liu, and Q. He, Molecules, 2019, 24(6), 1178.

[5] A. K. Baytak, E. Akbaş, and M. Aslanoglu, Anal. Chim. Acta, 2019, 1087, 93-103.

[6] X. Wu, X. Zhang, C. Zhao, and X. Qian, Talanta, 2018, 179, 836-844.

[7] K. Marquez-Mariño, J. Penagos-Llanos, O. GarcíaBeltrán, E. Nagles, and J. J. Hurtado, Electroanalysis, 2018, 30(11), 2760-2767.

[8] Y. Ya, C. Jiang, T. Li, J. Liao, Y. Fan, Y. Wei, F. Yan, and L. Xie, Sensors, 2017, 17(3), 545.

[9] J. Penagos-Llanos, O. García-Beltrán, J. A. Calderón, E. Nagles, and J. J. Hurtado,. Electroanalysis, 2019, 31(4), 695-703.

[10] J. Penagos-Llanos, J. A. Calderón, E. Nagles, and J. J. Hurtado, J. Electroanal. Chem., 2019, 833, 536-542.

[11] F. Ye, C. Feng, N. Fu, H. Wu, J. Jiang, and S. Han,. Appl. Surf. Sci., 2015, 357, 1251-1259.

[12] W. Zhang, R. Yuan, Y. Chai, Y. Zhang, and S. Chen, Sensor.Actuat. B-Chem., 2012, 166, 601-607.

[13] N. A. Nia, M. M. Foroughi, S. Jahani, M. ShahidiZandi, and N. Rastakhiz, J. Electrochem. Soc., 2019, 166(6), B489.

[14] A. Umara, A. A. Ibrahim, R. Kumar, T. Almas, P. Sandal, M.S. Al-Assiri, M. H. Mahnashi, B.Z. AlFarhan, and S. Baskoutas, Ceramics Int., 2020, 46(4), 51415148.

[15] X. Wang, Y. Li, Y. Zhou, and Y. He,. Anal. Methods, 2019, 11(43), 5613-5622.

[16] T. Gan, J. Sun, W. Meng, L. Song, and Y. Zhang, , Food Chem., 2013, 141(4), 3731-3737.

[17] Q. He, J. Liu, X. Liu, G. Li, P. Deng, J. Liang, and D. Chen, , Sensors, 2018, 18(6), 1911.

[18] Y.H. Li, J Zhu, L Dai, and L Wang, Advanced Materials Research, 2012, 554, 430-435.

[19] M. Arvand, Y. Parhizi, and S. H. Mirfath, Food Anal. Methods, 2016, 9(4), 863-875.

[20] L. J. Stevens, T. Kuczhek, J. R. Burgess, M. A. 
Stochelski, L. E. Arnold, and L. Galland,. Nutr. Rev., 2013, 71(5), 268-281.

[21] K. Rovina, L. Anak Acung, S. Siddiquee, J. H. Akanda and S. Md Shaarani, Food Anal. Methods 2017, 10(3), 773-787.

[22] K. Rovina, S. Siddiquee and S. Md Shaarani, Critical Reviews in Analytical Chemistry, 2017, 47(4), 309-324.

[23] Md. M. Rahman and J.J. Lee, J. Electrochem. Sci. Technol. 2019, 10, 185-195.

[24] J. Yu and T.H Kim, J. Electrochem. Sci. Technol. 2017, 8(4), 274-281.

[25] K. Ghanbari and S. Bonyadi, J. Electrochem. Sci. Technol., 2020, 11(1), 68-83.

[26] P. Viswanathan and R.Ramaraj, Sensor Actuat. B-Chem., 2018, 270, 56-63.

[27] V. Perumal, K. Y. Jin and H. Jong Dal, Langmuir, 2020, 36(13), 3452-3460.

[28] Md. M. Rahman, X.B. Li, Y.D. Jeon, H.J. Lee, S. J. Lee and J.J. Lee, J. Electrochem. Sci. Technol. 2012, 3(2),
90-94.

[29] P. Viswanathan, S. Manivannan and R. Ramaraj, RSC Adv., 2015, 5(67), 54735-54741.

[30] P. Viswanathan, R. Ramaraj, J. Molecular Catalysis A: Chemical, 2016, 424, 128-134.

[31] J. Penagos-Llanos, O. García-Beltrán, J.A .Calderón, J. J. Hurtado-Murillo, E. Nagles, and J. J. Hurtado, J. Electroanal. Chem., 2019, 852, 113517.

[32] T. Gan, J. Sun, S. Cao, F. Gao, Y. Zhang, and Y. Yang, Electrochim. Acta, 2012, 74, 151-157.

[33] N. Nuñez-Dallos, M. A. Macías, O. García-Beltrán, J. A. Calderón, E. Nagles, and J. Hurtado, J. Electroanal. Chem., 2018, 822, 95-104.

[34] P. A. Kolozof, A. B. Florou, K. Spyrou, J. Hrbac, and M. I. Prodromid, Sensor. Actuat. B-Chem., 2020, 304, 127268.

[35] L. Ji, Q. Cheng, K. Wu, and X. Yang,. Sensor Actuat. BChem., 2016, 231 12-17. 